\section{Mucosal bridge due to reflux esophagitis}

\section{Keiichiro Kume, Ichiro Yoshikawa \\ Third Department of Internal Medicine, University of Occupational and \\ Environmental Health, Japan; School of Medicine, Kitakyusyu, Japan}

\section{Introduction}

Mucosal bridges have most often been observed in the colon, associated with inflammatory bowel disease. Though reflux esophagitis is a common disease that can easily cause a mucosal bridge, we report this case because of its rarity.

\section{Case Report}

A 28-year old man had congenital dysphagia due to intracerebral neurofibroma. He visited our hospital complaining of heartburn and occasional coffee residue-like vomiting for half a year. Esophagoscopy revealed a mucosal bridge in the middle part of the esophagus (Figure 1). This lesion was destroyed spontaneously by deeper insertion of the endoscope. Moreover, esophagoscopy showed linear mucosal breaks between the middle and lower body of the esophagus (Figure 2). Therefore, he was diagnosed as having a mucosal bridge due to reflux esophagitis.

\section{Discussion}

A mucosal bridge in the esophagus is a rare condition that can be caused by congenital anomalies, ${ }^{1}$ mediastinal radiotherapy, ${ }^{2}$ esophageal variceal sclerotherapy, ${ }^{3}$ a nasoenteric feeding tube, ${ }^{4}$ and Crohn's disease. ${ }^{5,6}$ Only one case with a mucosal bridge due to reflux esophagitis has been previously reported. ${ }^{7}$ An acquired mucosal bridge due to inflammatory processes may arise anywhere from the esophagus to the colon. The pathogenesis of mucosal bridge has been a subject of speculation. It was reported that mucosal bridge formation may be related to undermining of the mucosa by ulceration, followed by healing with re-epithelialization of the mucosal undersurface and formation of a mucosal tube attached at each end to the non-ulcerated wall. ${ }^{8}$ Alternatively, it may simply represent the attachment of the free ends of pseudopolyps to the adjacent mucosa. ${ }^{3}$ We presume that chronic, repetitive, esophageal ulceration and healing led to the formation of the mucosal bridge through these mechanisms.

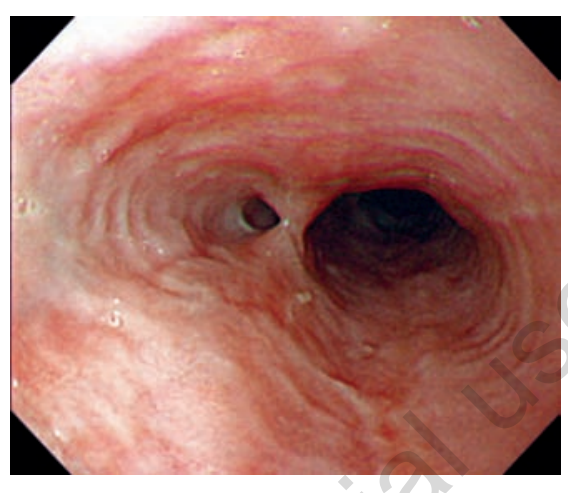

Figure 1. Esophagoscopy revealed a mucosal bridge in the middle part of the esophagus.

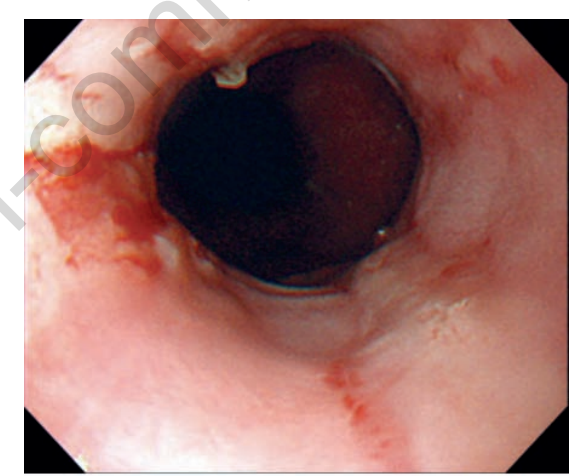

Figure 2. Esophagoscopy showed linear mucosal breaks between middle and lower body of the esophagus.
Correspondence: Keiichiro Kume, Third Department of Internal Medicine, University of Occupational and Environmental Health, Japan, School of Medicine 1-1, Iseigaoka, Yahatanishiku, Kitakyusyu 807-8555, Japan.

E-mail: k-kume@med.uoeh-u.ac.jp

Key words: inflammatory bowel disease, reflux esophagitis.

Received for publication: 3 July 2009.

Revision received: 8 October 2009

Accepted for publication: 9 October 2009 .

This work is licensed under a Creative Commons Attribution 3.0 License (by-nc 3.0).

(c) Copyright K. Kume, I. Yoshikawa 2009

Licensee PAGEPress, Italy

Gastroenterology Insights 2009; 1:e4

doi:10.4081/gi.2009.e4

\section{References}

1. Chang FY, Lai KH, Lee SD, et al. Asymptomatic mucosal bridge of the upper esophagus. Gastrointest Endosc 1989;35: 472-3.

2. Mohanadas KM, Swroop VS, Iyer G, et al. Mucosal bridge of the esophagus. Am J Gastroenterol 1990;85:907-8.

3. Gottfried EB, Goldberg HJ. Mucosal bridge of the distal esophagus after esophageal variceal sclerotherapy. Gastrointest Endosc 1985;31:267-9.

4. Buchman AL, Waring JP. Mucosal bridge formation in the esophagus caused by injury from a nasoenteric feeding tube. $\mathrm{J}$ Pareter Enter Nutr 1994;18:278-9.

5. Honda S, Sugimoto K, Iwasaki H, et al. Multiple mucosal bridge formation in the esophagus in a patient with Crohn's disease. Endoscopy 1998;30:S37-8.

6. Samach M, Train J. Demonstration of mucosal bridge in Crohn's colitis. Am J Gastroenterol 1980;74:50-4.

7. Papazian A, Capron JP, Sevenet F, et al. Mucosal bridge of the distal esophagus related to reflux esophagitis. Gastrointest Endosc 1984:30:217-8.

8. Waye JD. Endoscopy in inflammatory bowel disease. J Clin Gastroenterol 1980;9:287. 